\title{
Platinum-based neoadjuvant chemotherapy in BRCA1-positive breast cancer: a retrospective cohort analysis and literature review
}

Nikolai Havn Sæther ${ }^{1 *}$ (D), Elina Skuja ${ }^{1,2}$, Arvids Irmejs $^{1,3}$, Jelena Maksimenko ${ }^{1,3}$, Edvins Miklasevics $^{1}$, Gunta Purkalne $e^{1,2}$ and Janis Gardovskis ${ }^{1}$

\begin{abstract}
Background: There is increasing evidence of high platinum sensitivity in BRCA-associated breast cancer. However, evidence from randomized trials is lacking. The aim of this study was to analyze the results of platinum-based chemotherapy for BRCA1-positive breast cancer in a neoadjuvant setting.

Methods: A retrospective study was performed by obtaining information from patient files. The results were compared with the available data from a literature review.

Results: Twelve female patients with BRCA1 gene mutations who had stage I to III breast cancers were eligible for evaluation. They received platinum-based neoadjuvant chemotherapy between 2011 and 2016. Eleven patients received a combination of cisplatin and doxorubicin, and one patient received carboplatin and docetaxel. All patients underwent mastectomy after chemotherapy. Ten patients (83\%) achieved pathological complete remission $(p C R)$. The observed $p C R$ rate was comparable to existing results found in similar studies.

Conclusion: The results of the study confirm the high pCR rate in BRCA1-positive breast cancer after platinum-based neoadjuvant chemotherapy. Larger randomized studies and longer follow-up times are necessary to evaluate the role of platinum-based therapies in BRCA1-positive breast cancer.
\end{abstract}

Keywords: Neoadjuvant, Cisplatin, Platinum, BRCA1, Breast cancer, pCR

\section{Background}

Hereditary breast cancer accounts for approximately $5-10 \%$ of all breast cancer cases. BRCA1/2 gene mutations are responsible for approximately two-thirds of hereditary breast cancers [1]. The BRCA genes are tumor suppressor genes that encode proteins that are involved in homologous recombination (HR) repair. HR is the most common repair mechanism for double strand breaks during the DNA replication process. Mutations in the BRCA gene result in genomic instability and subsequent malignant processes. The platinum agent introduces intra-strand crosslinks. Due to faulty DNA-repair proteins from the pathogenic $B R C A 1$ mutation, cellular protein synthesis and

\footnotetext{
* Correspondence: nikolai.sather@gmail.com

${ }^{1}$ Riga Stradins University, Riga, Latvia

Full list of author information is available at the end of the article
}

replication are reduced, and eventually, cells undergo apoptosis. BRCA-associated breast cancers are often triple negative breast cancers (TNBCs). Due to significant differences in chemotherapy sensitivity that depend on hormone receptor status, various chemotherapy regimens have been tested in adjuvant and neoadjuvant settings for BRCAassociated breast cancer. Attempts to understand the role of $B R C A$ genes in and sensitivity of cancer cells to DNA damaging agents in BRCA mutation carriers have reestablished interest in platinum agents in the context of breast cancer treatment.

Several studies have shown the sensitivity of $B R C A$ related breast cancer to platinum agents, such as cisplatin and carboplatin, and more studies will follow. The ESMO clinical practice guidelines [2] for primary breast cancer published in 2015 do not recommend platinum agents for 
Table 1 Basal clinical characteristics of neoadjuvant patients, $n=12$

Characteristic
Age, years
Mean
Range
BRCA1 mutation
Exon 20 c.5266dupC (BIC: 5382insC)
Exon 11 c.4035delA (BIC: 4154delA)
Clinical tumor size
T1
T2
T3
Clinical nodal status
N0
N1
N2
N3

Estrogen receptor level

Positive

Negative

Missing

Progesterone receptor level

Positive

Negative

Missing

HER2 status

Positive

Negative

Missing

Differentiation

Grade I

Grade II

Grade III

Missing

Histology

Ductal

Medullary

Missing

Chemotherapy

Cisplatin + Doxorubicin

Carboplatin + Docetaxel

Pathological remission

Complete

Partial

$\begin{array}{ll}\text { No. } & \text { Percent } \\ 38 & \\ 28-56 & \\ 8 & \\ 4 & 66 \\ & 34 \\ 5 & \\ 5 & 42 \\ 2 & 42 \\ & 17\end{array}$

6

5

0

1

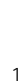

1

10

1

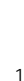

10

1

18

8

3

0

4

8

Table 1 Basal clinical characteristics of neoadjuvant patients, $n=12$ (Continued)

\begin{tabular}{lll}
\hline Characteristic & No. & Percent \\
\hline Salpingoopherectomy & 7 & 58 \\
No & 5 & 42 \\
Yes & & \\
Postoperative radiation & 8 & 66 \\
No & 4 & 33 \\
Yes & 4 \\
\hline
\end{tabular}

routine use for BRCA1/2 mutation carriers; however, these guidelines state that adding a platinum compound to NACT, after discussion with the patient, is acceptable. The ESO-ESMO 3rd international consensus guidelines for advanced breast cancer (ABC3) [3] published on December 5th, 2016, recommend a platinum regimen chemotherapy for $B R C A$-associated TNBC if not previously administered.

The aim of this study was to retrospectively evaluate platinum-based neoadjuvant chemotherapy for BRCA1positive breast cancers.

\section{Methods}

A retrospective evaluation was made of platinum-based neoadjuvant chemotherapy in breast cancer patients with $B R C A 1$ gene mutations who were treated at the breast unit at Pauls Stradins Clinical University Hospital (PSCUH). Patient data were collected from the hospital database, along with the respective patient history and chemotherapy chart from the Clinic of Oncology at PSCUH. This retrospective evaluation was approved by Riga Stradins University Ethical committee (Nr.55/ 27.10.2016). Patients with diagnosed invasive breast cancers and confirmed BRCA1 gene mutations who received platinum-based chemotherapy in the neoadjuvant setting were included in the evaluation.

Genomic DNA was isolated from peripheral blood cells using the FlexiGene DNA Kit (Qiagen, Germany). Screening of the three most common BRCA1 mutations in Latvia, namely, c.4035delA (BIC: 4154delA), c.5266dupC (BIC: 5382insC) and c.181 T > G (BIC: $300 \mathrm{~T}>\mathrm{G} / \mathrm{C61G}$ ), was performed by multiplex PCR.

Insufficient patient data was the exclusion criterion. Pathological complete response was defined as the complete disappearance of an invasive tumor. The follow-up time was the time from mastectomy to February 2017.

\section{Study population}

Twelve BRCA-associated patients were eligible for this evaluation during the period from 2011 to February 2017.

The clinical characteristics of the patients are presented in Table 1. All patients except one received a regimen of $50-75 \mathrm{mg} / \mathrm{m}^{2}$ cisplatin and $50-60 \mathrm{mg} / \mathrm{m}^{2}$ 
doxorubicin (one patient received carboplatin AUC5 and $75 \mathrm{mg} / \mathrm{m}^{2}$ docetaxel) every 3weeks for three to 6 cycles. The treatment regimens are presented in Table 2. Four patients had received postoperative radiation therapy. One patient had received additional adjuvant cisplatin and doxorubicin for 2 cycles. Seven patients (58\%) received 6 cycles with platinum agents in all cycles.

All 12 patients $(100 \%)$ underwent therapeutic mastectomies on the affected side and risk reductive mastectomies on the contralateral side if applicable, except one patient who refused risk reductive mastectomy. A total of 23 mastectomies were performed in 12 patients: three simple, six skin-sparing and 14 nipple-sparing mastectomies. In 10 out of 12 cases immediate reconstruction was carried out. Five patients $(42 \%)$ had prophylactic salpingoophorectomies performed after breast surgery. The mean observation time after breast surgery was 24 (range one - 63 months). Toxicity was not assessed in this evaluation.

\section{Results}

Ten (83\%) out of 12 patients achieved pCR after neoadjuvant chemotherapy. Two patients (17\%) had residual cancer after NACT with partial response or stable disease. The proportions of the subgroups of those who achieved pCR are presented in Table 3. The pCR rates according to clinical stage I, II and III were $100 \%, 86 \%$ and $50 \%$, respectively. Eight $(80 \%)$ out of 10 patients with confirmed negative estrogen and progesterone receptor status achieved pCR. Five (83\%) out of six patients with positive lymph node status prior to surgery achieved pCR. (Similarly, five (83\%) out of six patients with node-negative disease achieved $\mathrm{pCR}$ ).

Eleven patients are alive today, and one patient died due to brain metastases 15 months after breast cancer diagnosis. All 10 patients with $\mathrm{pCR}$ are disease free to

Table 2 NACT regimens of patients evaluated

\begin{tabular}{llll}
\hline Agents & Dosages & Cycles & $\begin{array}{l}\text { No. of } \\
\text { patients }\end{array}$ \\
\hline Fluorouracil + doxorubicin + & $500 \mathrm{mg} / \mathrm{m}^{2}+50 \mathrm{mg} / \mathrm{m}^{2}+$ & 3 & 1 \\
cyclophosphamide (FAC) & $500 \mathrm{mg} / \mathrm{m}^{2}$ & \\
Cisplatin + doxorubicin & $70 \mathrm{mg} / \mathrm{m}^{2}+55 \mathrm{mg} / \mathrm{m}^{2}$ & 3 & \\
Cisplatin + doxorubicin & $60 \mathrm{mg} / \mathrm{m}^{2}+60 \mathrm{mg} / \mathrm{m}^{2}$ & 3 & 1 \\
Docetaxel & $75 \mathrm{mg} / \mathrm{m}^{2}$ & 2 & \\
Cisplatin + doxorubicin & $50 \mathrm{mg} / \mathrm{m}^{2}+50 \mathrm{mg} / \mathrm{m}^{2}$ & 6 & 3 \\
& $75 \mathrm{mg} / \mathrm{m}^{2}+50 \mathrm{mg} / \mathrm{m}^{2}$ & 5 & 1 \\
& $60 \mathrm{mg} / \mathrm{m}^{2}+60 \mathrm{mg} / \mathrm{m}^{2}$ & 6 & 2 \\
& $60 \mathrm{mg} / \mathrm{m}^{2}+60 \mathrm{mg} / \mathrm{m}^{2}$ & 4 & 1 \\
& $75 \mathrm{mg} / \mathrm{m}^{2}+50 \mathrm{mg} / \mathrm{m}^{2}$ & 4 & 1 \\
& $50 \mathrm{mg} / \mathrm{m}^{2}+60 \mathrm{mg} / \mathrm{m}^{2}$ & 6 & 1 \\
& AUC $-5+60 \mathrm{mg} / \mathrm{m}^{2}$ & 6 & 1 \\
\hline
\end{tabular}

Table 3 Proportions of patient subgroups achieving pCR

\begin{tabular}{llll}
\hline Characteristic & No. with pCR & Total no. & $\%$ PCR \\
\hline Age, years & 8 & 8 & 100 \\
$20-40$ & 1 & 2 & 50 \\
$41-50$ & 1 & 2 & 50 \\
$51-60$ & & 3 & \\
Stage & 3 & 7 & 100 \\
I & 6 & 2 & 86 \\
II & 1 & & 50 \\
III & 1 & 1 & 100 \\
Estrogen receptor & & 10 & 80 \\
Positive & 8 & 1 & 100 \\
Negative & 1 & & 83 \\
Missing & & 6 & \\
Lymph nodes & 5 & 6 & \\
Positive & 5 & &
\end{tabular}

date according to the available data. The mean observation time for the patient group with $\mathrm{pCR}$ is 25 months (range 6-63 months). Table 4 presents the characteristics of the two patients who did not achieve pCR.

\section{Discussion}

Our findings from the retrospective evaluation at the breast unit of PSCUH suggested that platinum-based neoadjuvant chemotherapy was highly effective in breast cancer patients with $B R C A 1$ gene mutations. In our patient group, 12 patients received platinum-based NACT. pCR was observed in 10 patients (83\%), and partial remission or stable disease was observed in two patients (17\%). T. Byrski et al. [4] were the first to apply platinum-based chemotherapy in studies targeting $B R C A$ mutation carriers specifically. As seen in Table 5, the pCR rates ranged from 59\% to $83 \%$ in the evaluated studies. Our results matched these findings and confirmed the sensitivity of BRCA-associated breast cancer to platinum agents. In the neoadjuvant studies by T. Byrski [4, 5] and V. Moysienko [6], the authors applied cisplatin monotherapy. The patients in the current evaluation received cisplatin and doxorubicin (one patient received carboplatin and docetaxel). There were no available data on this combination for patients with BRCAassociated breast cancer. The results indicated that the addition of anthracycline to a platinum agent in the neoadjuvant setting produces equivalent or better results than monotherapy in terms of pCR. Most of the 12 patients included in this evaluation had cancers that were diagnosed early. Seven patients had stage II, three patients had stage I, and two patients had stage III. These characteristics are comparable to the trial of T. Byrski et al. [5], where a pCR of $61 \%$ was achieved. 
Table 4 Characteristics of patients not achieving pCR

\begin{tabular}{lll}
\hline Patient & 1 & 2 \\
\hline Age & 49 & 56 \\
CTNM/pyTNM & T2NOMO/pyT2NOMO & T3N3M0/pyT3N3aM0 \\
Histology & Ductal carcinoma & Ductal carcinoma \\
Grade & 3 & 3 \\
ER/PR/HER2 & Triple negative & Triple negative \\
NACT regimen & FAC (1000 mg $+100 \mathrm{mg}+1000 \mathrm{mg}) 3$ cyclesCisplatin+ & Cisplatin+Doxorubicin (80 mg + 90 mg 4 cycles, \\
& Doxorubicin $(140 \mathrm{mg}+110 \mathrm{mg}) 3$ cycles & $80 \mathrm{mg}+85 \mathrm{mg} 2$ cycles $)$ \\
Pre-tx tumor size & $45 \mathrm{~mm}$ & X (extensive, diffuse, difficult to evaluate the size) \\
Post-tx tumor size & $25 \mathrm{~mm}$ & $65 \mathrm{~mm}$ \\
Operation & Unilateral mastectomy & Bilateral mastectomy \\
Lymphadenectomy & Yes & Yes \\
Adjuvant CT & No & No \\
Postoperative radiation & Yes & Yes \\
Progression & No & Brain metastases, PFS 12 months, OS 15 months \\
\hline
\end{tabular}

The BRCA1 founder mutations in our study included c.4035delA (BIC: 4154delA) and c.5266dupC (BIC: 5382insC). These are the same mutations examined in the study by Byrski et al.; however, C61G was also included in their study population but not in ours. Our results need to be verified in populations with other mutations.

The protocols for all patients in the reviewed neoadjuvant studies included the administration of the standard $\mathrm{AC}$ regimen as the adjuvant chemotherapy regardless of the level of response. The patients who achieved pCR in our study did not receive any adjuvant chemotherapy. Our observation times for patients with $\mathrm{pCR}$ varied from 1month to 63 months, and currently, the mean observation time is 25 months. All patients except one are still alive according to the available data. A comprehensive assessment of the survival rate of our platinum-based NACT will require additional follow-up. Observing the progression-free survival (PFS) rate of our patient group with pCR will provide highly interesting information in the future. No studies have properly assessed PFS that is specific to breast cancer patients with $B R C A 1$ mutations receiving only neoadjuvant platinum-based chemotherapy without adjuvant treatment.

Platinum agents also showed efficacy for BRCA1 mutation carriers with advanced breast cancer. A $B R C A 1$ gene mutation was a good predictor of an increased response rate compared with wild-type BRCA1 [7-9]. The best evidence on platinum efficacy compared to standard therapy to date is presented by Telli et al. in the TNT trial [7]. The authors randomized carboplatin vs docetaxel in patients with metastatic TNBC. They observed a carboplatin response rate of $68 \%$ vs a docetaxel rate of $33 \%(P=0.03)$ in the subgroup of 43 patients having $B R C A 1 / 2$ mutations. Further research is needed on metastatic BRCA-associated breast cancer.

There is a substantial amount of research on TNBC. In a study comprising 1824 patients with TNBC unselected for family history, $8.5 \%$ had a BRCA1 mutation, and $2.7 \%$ had a BRCA2 mutation [10]. The patients with BRCAassociated breast cancer represent a small subset of breast cancer patients. This is probably the reason for the lack of data for this specific patient population. To date, there are no available data from randomized trials that specifically target BRCA1 gene mutation carriers with breast cancer. Evidence from the Maksimenko study [11] indicated that carriers of a germline BRCA1 founder mutation (4153delA a 5382insC) had significantly improved prognoses at any stage compared to carriers of wild-type BRCA who had TNBC, even though only $7.8 \%$ of patients in this study had received platinum-based chemotherapy. These results may indicate that BRCA1 mutation carriers have higher chemosensitivity.

Table 5 Platinum-based neoadjuvant chemotherapy in BRCA-associated breast cancer

\begin{tabular}{lllll}
\hline Author & $n$ & Setting & Regimen & Efficacy \\
\hline Byrski et al. 2010 [4] & 12 & Neoadjuvant & Cisplatin & pCR rate: 83\% \\
Byrski et al. 2014 [5] & 107 & Neoadjuvant & Cisplatin & pCR rate: 61\% \\
Moiseyenko et al. 2015 [6] & 5 & Neoadjuvant & Cisplatin & pCR rate: 60\% \\
Sharma et al. 2016 [13] & 30 & Neoadjuvant & Carboplatin+Docetaxel & pCR rate: 59\% \\
\hline
\end{tabular}


The toxicity of chemotherapy was not evaluated. Platinum agents are known to cause mild to severe toxicity [12]. Cisplatin seems to be the drug that has the most evidence of efficacy in BRCA-associated breast cancer. No evidence from randomized trials exists on which platinum agent is more effective in BRCA-associated breast cancer. Further data are needed. A transition from cisplatin to carboplatin-based chemotherapy would likely benefit patients in terms of fewer side effects and higher tolerance to recommended platinum dosages.

\section{Conclusion}

The results of the study confirm the high $\mathrm{pCR}$ rate of BRCA1-positive breast cancer after platinum-based neoadjuvant chemotherapy. Larger randomized studies and longer follow-up times are necessary to evaluate the role of platinum-based therapies in BRCA1-positive breast cancer.

\section{Abbreviations}

NACT: Neoadjuvant chemotherapy; OS: Overall survival; pCR: Pathological complete remission; PFS: Progression-free survival; PSCUH: Pauls Stradins Clinical University Hospital; TNBC: triple negative breast cancer

\section{Funding}

This work was supported by State Research Program "Biomedicine for the public health (BIOMEDICINE)" project 5 "Personalised cancer diagnostics and treatment effectiveness evaluation".

\section{Availability of data and materials}

The datasets used and/or analyzed during the current study are available from the corresponding author on reasonable request.

\section{Authors' contributions}

$\mathrm{NHS}$ and ES wrote the paper. NHS managed the database and computed the results. All others participated in the study design, interpreted the results, commented on the manuscript and approved the final manuscript.

\section{Ethics approval and consent to participate}

This retrospective evaluation was approved by the RSU Ethical committee (Nr.55/ 27.10.2016)

\section{Consent for publication}

Consent was obtained from all participants in this study.

\section{Competing interests}

The authors declare that they have no competing interests.

\section{Publisher's Note}

Springer Nature remains neutral with regard to jurisdictional claims in published maps and institutional affiliations.

\section{Author details}

${ }^{1}$ Riga Stradins University, Riga, Latvia. ${ }^{2}$ Pauls Stradins Clinical University Hospital, Clinic of Oncology, Riga, Latvia. ${ }^{3}$ Pauls Stradins Clinical University Hospital, Breast unit, Riga, Latvia.

Received: 28 January 2018 Accepted: 13 April 2018

Published online: 27 April 2018

\section{References}

1. Wooster R, Weber B. Breast and ovarian cancer. N Engl J Med. 2003:348(23):2339-47.

2. Senkus E, Kyriakides S, Ohno S, Penault-Llorca F, Poortmans P, Rutgers E, et al. Primary breast cancer: ESMO clinical practice guidelines. Ann Oncol. 2015;26(5):v8-v30.
3. Cardoso F, Costa A, Senkus E, Aapro M, André F. Barrios CH et al. 3rd ESO-ESMO international consensus guidelines for advanced breast Cancer (ABC 3). Ann Oncol. 2017;28(1):16-33.

4. Byrski T, Gronwald J, Huzarski T, Grzybowska E, Budryk M, Stawicka M, et al. Pathologic complete response rates in young women with BRCA1-positive breast cancers after neoadjuvant chemotherapy. J Clin Oncol. 2010;28(3):375-9.

5. Byrski T, Huzarski R, Dent E, Marczyk M, Jasiowka J, Gronwald J. Pathologic complete response to neoadjuvant cisplatin in BRCA1-positive breast cancer patients. Breast Cancer Res Treat. 2014;147(2):401-5.

6. Moysenko V, Dolmatov G, Moiseyenko F, Ivantsov A, Volkov N, Chubenko V, et al. High efficacy of cisplatin neoadjuvant therapy in a prospective series of patients carrying BRCA1 germ-line mutation. Med Oncol. 2015;32(4):89.

7. Tutt A, Ellis P, Kilburn L, Gilett C, Pinder S, Abraham J, et al. The TNT trial: a randomized phase III trial of carboplatin (C) compared with docetaxel (D) for patients with metastatic recurrent or locally advanced triple negative or BRCA1/2 breast cancer. Cancer Res. 2014;1(75 (9 Supplement)):S3-01.

8. Byrski T, Dent R, Blecharz P, Foszczynska-Kloda M, Gronwald J, Huzarski T, et al. Results of a phase II open-label, non-randomized trial of cisplatin chemotherapy in patients with BRCA1-positive metastatic breast cancer. Breast Cancer Res. 2012;20(14(4)):R110.

9. Isakoff SJ, Mayer EL, He L, Traina TA, Carey LA, Krag KJ, et al. TBCRC009: a multicenter phase II clinical trial of platinum monotherapy with biomarker assessment in metastatic triple-negative breast Cancer. J Clin Oncol. 2015;10(33(17)):1902-9.

10. Couch FJ, Hart SN, Sharma P, Toland AE, Wang X, Miron P, et al. Inherited mutations in 17 breast cancer susceptibility genes among a large triple-negative breast cancer cohort unselected for family history of breast cancer. J Clin Oncol. 2015;1(33(4)):304-11.

11. Maksimenko J, Irmejs A, Nakazawa-Miklasevica M, Melbarde-Gorkusa I, Trofimovics G, Gardovskis J, et al. Prognostic role of BRCA1 mutation in patients with triple-negative breast cancer. Oncol Lett. 2014;7(1):278-84

12. McWhinney SR, Goldberg RM, McLeod HL. Platinum neurotoxicity pharmacogenetics. Mol Cancer Ther. 2014;8(1):10-6.

13. Sharma P, López-Tarruella S, García-Saenz JA, Ward C, Connor CS, Gómez HL, et al. Efficacy of neoadjuvant carboplatin plus docetaxel in triple-negative breast Cancer: combined analysis of two cohorts. Clin Cancer Res. 2017;23(3):649-57.

\section{Ready to submit your research? Choose BMC and benefit from:}

- fast, convenient online submission

- thorough peer review by experienced researchers in your field

- rapid publication on acceptance

- support for research data, including large and complex data types

- gold Open Access which fosters wider collaboration and increased citations

- maximum visibility for your research: over $100 \mathrm{M}$ website views per year

At BMC, research is always in progress.

Learn more biomedcentral.com/submissions 